\title{
JOURNAL.RU
}

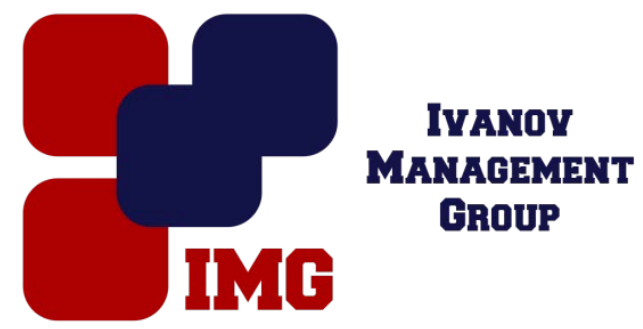

Давлетова Г.Р. Высшая школа бизнеса Казанского Федерального Университета Казань, Россия

doi: 10.18411/lj-31-10-2016-2-03

idsp 000001:lj-31-10-2016-2-03

\section{Внутренний аудит как одна из форм внутреннего контроля}

Научный руководитель: Плотникова Л.А.

В период все более ускоряющегося процесса экономической глобализации предприятия сталкиваются в своей деятельности с различными рисками, расширяющих создание системы внутреннего контроля и антикризисного управления в целях обеспечения устойчивого развития предприятий. Внутренний контроль фактов хозяйственной жизни в современной системе управления является одним из важных ее компонентов и позволяет снизить риски, имеющиеся в деятельности любого предприятия.В свою очередь, как показывает практика, система внутреннего контроля состоит из пяти основных элементов, а именно: контрольной среды, процедур по оценке риска, мероприятий по процедурам осуществления контроля, информационной системы и мониторинга средств контроля.

По нашему мнению, внутренний аудит является одной из форм контроля, a, следовательно, и частью системы внутреннего контроля на предприятии, и предназначен в целом для повышения эффективности системы внутреннего контроля.Взаимосвязь системы внутреннего контроля и процедур внутреннего аудита, по нашему мнению, можно представить схематично на рисунке 1. 


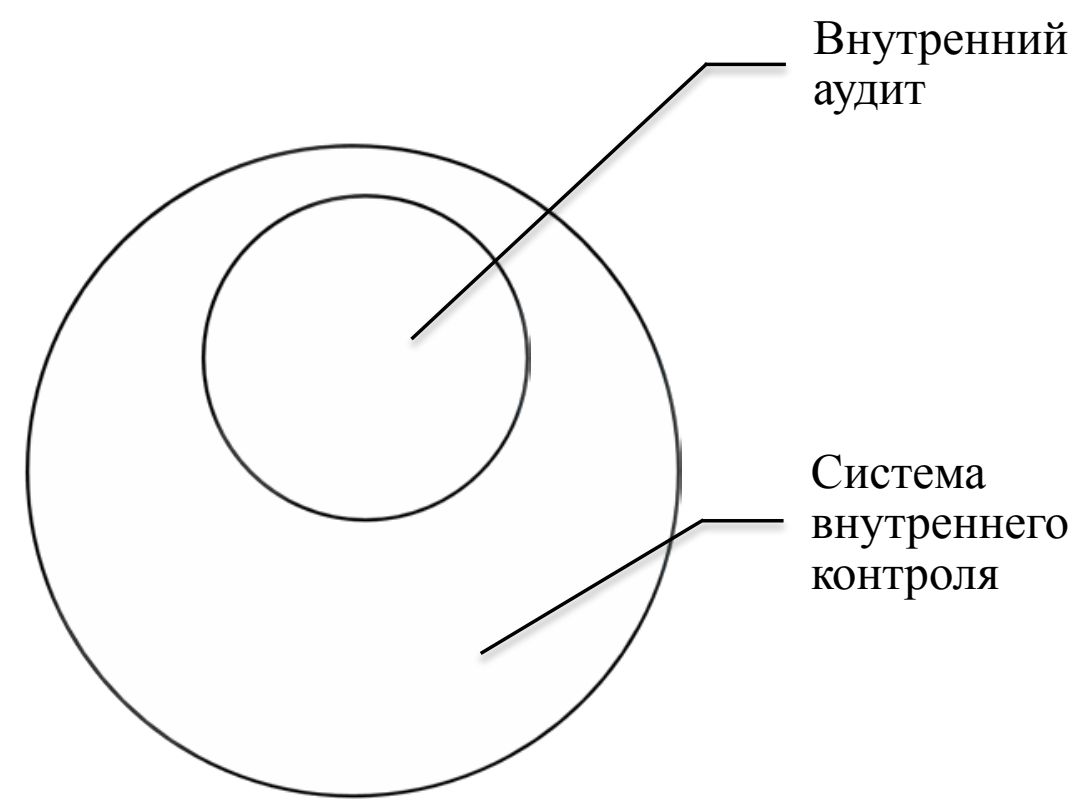

Рис. 1 Взаимосвязь системы внутреннего контроля и системы внутреннего аудита

Мы считаем, что процедуры проведения внутреннего аудита можно отнести к двум элементам системы внутреннего контроля - информационной системе и мониторингу средств контроля. Например, в части информационной среды в результате осуществления первоначального аудита фактов хозяйственной жизни на стадии их совершения на предприятии формируется информация о легальности и правомерности хозяйственных операций, что позволяет принять то или иное управленческое решение. Что касается мониторинга средств контроля, то в этой части также просматривается необходимость и важная роль внутреннего аудита, поскольку благодаря аудиту в виде проверки и тестирования средств контроля можно определить эффективность работы всей системы внутреннего контроля.

Эффективная система внутреннего контроля должна обеспечивать выполнение следующих требований:

- обеспечение того, чтобы бизнес-деятельность осуществлялась в соответствии с установленными полномочиями;

- обеспечениеправильного (достоверного) и полногоучета всех фактов хозяйственной жизни;

- осуществление функций управления с целью повышения эффективности деятельности; 
- обеспечение эффективного внедрения системы внутреннего контроля.

В соответствии с требованиями внутреннего контроля внутренний аудит является своего рода контролем выполнения аудиторских процедур, методов и задач для достижения поставленных целей. Проведение аудита необходимо для создания качественной и эффективной среды управления, а также для улучшения функционирования системы внутреннего контроля. Помимо всего прочего внутренний аудит играет незаменимую и уникальную роль также и в области управления рисками.

Внутренний аудит играет важную роль в области контроля, необходим для оценки разумности, эффективности и соответствия данных, чтобы оценить ситуацию для внутреннего контроля руководства. И аудит, и контроль дополняют друг друга, являются обязательными в части системы управления на предприятии. При определении качества внутреннего контроля необходимость внутреннего аудита гораздо выше, чем любые другие факторы, которые определяют форму аудита. Надежная система внутреннего контроля является основой для проведения аудита.Аудит не может быть проведен без надежной системы внутреннего контроля в качестве основы, так как информация бухгалтерского учета, финансовая информация будет неподтвержденной в части ее достоверности. Такое состояние на предприятии увеличит нагрузку внутреннего аудита, а также увеличит риск внутреннего аудита, тем самым сдерживая эффективное развитие системы внутреннего контроля.

Внутренний аудит является оценкой надежности и эффективности существующей системы внутреннего контроля, а внутренние аудиторы людьми, призванными непредвзято и профессионально провести такую оценку. Другими словами можно сказать, что внутренний аудит является независимой оценкой. И основной целью компании является обретение уверенности и надежности в использовании средств внутреннего контроля.

Критерием оценки производительности внутреннего аудита также служит степень достижения поставленной перед системой внутреннего аудита цели либо задачи, степень решения конкретных проблем. Критерии оценки качества системы внутреннего аудита показаны на рисунке 2. 


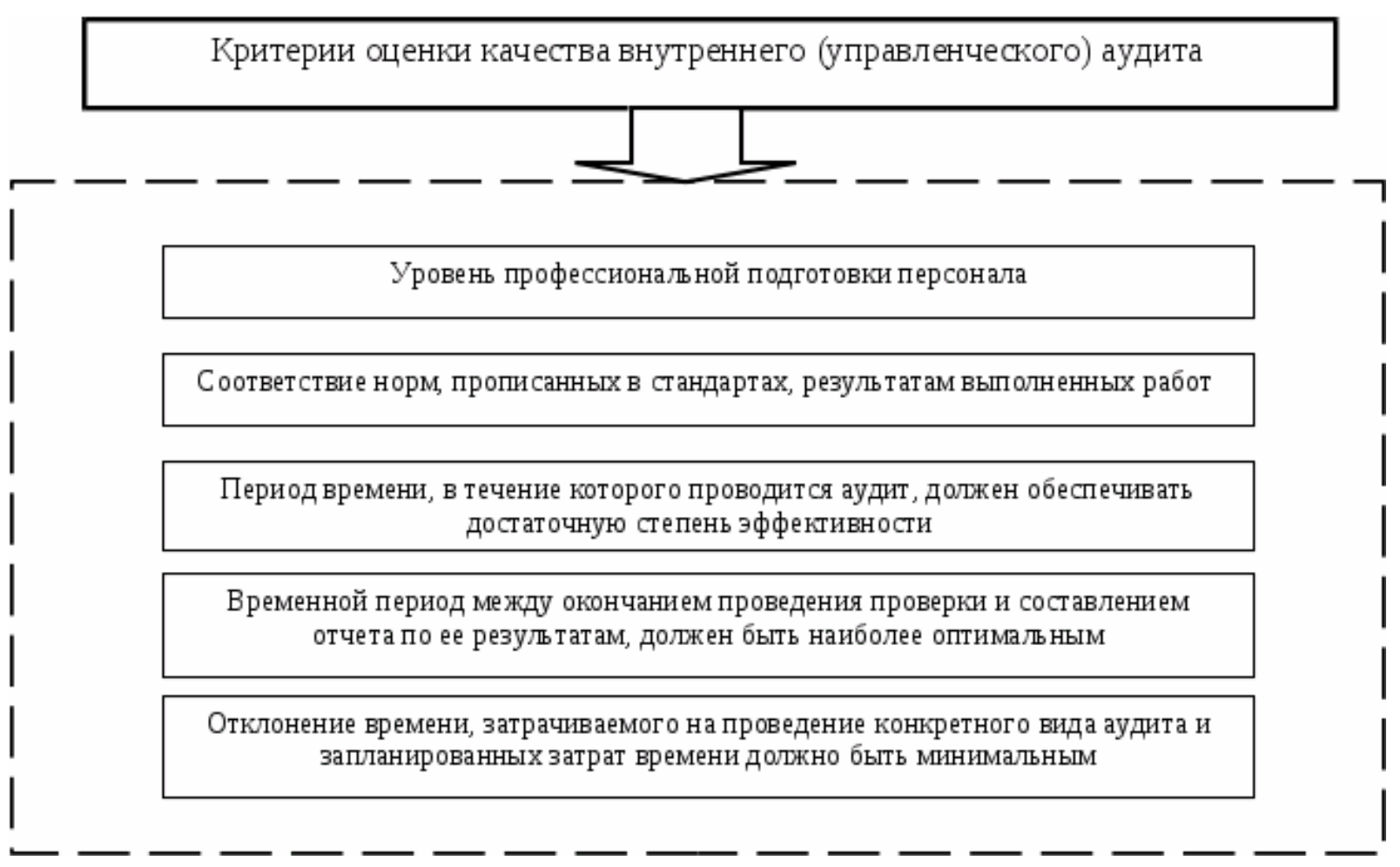

Рис. 2 Критерии оценки качества системы внутреннего аудита

Таким образом, предложенные критерии, используемые для оценки качества системы внутреннего аудита, должны соответствовать критериям, применяемым для оценки эффективности деятельности экономического субъекта в целом. Цели и задачи внутреннего аудита должны дополнять и соответствовать общим целям и задачам экономического субъекта. При выполнении этих условий система внутреннего аудита будет способствовать наиболее эффективному развитию экономического субъекта. 


\section{Литература}

1. Виноградов О.В., Мизиковский Е. А. Оценка аудиторами качества внутреннего контроля // Бухгалтерский учет.- 2015.

2. Каспина Р.Г. Реорганизация системы управления для целей формирования корпоративной отчетности // Казанская наука, 2013, № 9, с.108-111.

3. Каспина Р.Г., Плотникова Л.А. Раскрытие информации в бухгалтерской отчетности компаний с иностранными инвестициями // Аудит и финансовый анализ, № 1, 2009

4. Макаренко, Е.Н. Внутренний аудит в системе управления предприятием / Е.Н. Макаренко // Управленческий учет. - 2014.

5. Орлов С.Н. Внутренний аудит в современной системе корпоративного управления компанией // Инфра-М.- 2015г.

6. Плотникова Л.А. Особенности организации внутреннего контроля внешнеторговых сделок // Современные проблемы глобализации мирового хозяйства и социально-культурного развития человека: Материалы докладов итоговой научно-практической конференции.- Казань: «Отечество», 2014 - с.106-109.

7. Плотникова Л.А. Процедуры внутреннего контроля внешнеторговых сделок как инструмент снижения рисков экономического субъекта // Казанский экономический вестник. 2015, № 1(15) - с.21-24.

8. Плотникова Л.А. Современные подходы к процессу обучения и подготовки специалистов по учету // Профессиональное образование: исторические традиции и современность: Материалы Международной научно-практической конференции / Под общ.ред. профессора М.И. Абакарова. - Махачкала: НИЦ «Инноватика», 2016. -120 с. - с.50-54.

9. Сафина Д.И. Внутренний контроль фактов хозяйственной жизни организации // Сборник статей Международной научно-практической конференции «Инновация, технологии, наука». Ответственный редактор: СукиасянАсатур Альбертович.- Киров, 23 января 2016: Уфа, ООО «ОмегаСайнс», 2016. - 240 с. - с. $178-180$. 
10. Соловьева О.В., Сорокина К.В. Анализ тенденций развития зарубежной корпоративной отчетности // Аудит и финансовый анализ.- 2013.

11. Сонин А. "Внутренний аудит как важнейший элемент системы управления компанией" // Некоммерческое партнерство «Институт внутренних аудиторов»-2016. 